
A.S. Kolbin ${ }^{1,2}$, A.V. Kharchev ${ }^{3}$
${ }^{1}$ St. Petersburg State University, Russian Federation
${ }^{2}$ Regional Drug Safety Monitoring Center, Saint Petersburg, Russian Federation
${ }^{3}$ St. Petersburg State Pediatric Medical University, Russian Federation

\section{Safety of biopharmaceuticals and small molecules. Are there any differences?}

Author affiliation:

Kolbin Aleksei Sergeevich, $\mathrm{PhD}$, professor at the pharmacology department of the Saint Petersburg State University, head of the Regional Drug Safety Monitoring Center

Address: 8, Line 21, Vasilyevsky Island, St. Petersburg, 199106, tel.: +7 (921) 759-04-49, e-mail: Alex.kolbin@mail.ru

A considerable number of biopharmaceuticals have recently been introduced into clinical practice. Their role is becoming more and more important in managing various diseases, including incapacitating and life-threatening diseases. The authors systematically reviewed literary data from 1990 to 2013 dedicated to studying adverse side reactions to medicinal proteins. The authors used international databases to search for publications dedicated to this issue. As a result, this analysis involves studies describing adverse reactions of such biopharmaceuticals as immunosuppressants and antineoplastic agents. Differences between biopharmaceuticals and small molecules in the rate of adverse phenomena, structure and severity of their manifestations are shown. Classification of adverse reactions and possibility of its use in terms of biopharmaceuticals, recommendations and conclusions for the Russian pharmacovigilance system are given.

Keywords: pharmacovigilance, biopharmaceutical, safety, adverse side reactions and phenomena

(Pediatric pharmacology. 2013; 10 (3): 17-25)

\title{
RELEVANCE
}

A considerable amount of biopharmaceuticals (BP) used both in treating of various diseases (in vivo) and diagnostics (in vitro) have been introduced in the clinical practice within the last 10 years [1, 2].Medicinal proteins first became widely used in clinical medicine in 1950s. Generally, these were vaccines, serums, immunoglobulins and toxoids. To be more consistent, Koch's vaccines and tuberculin were probably the first BP (1890). Later, insulins, interferons, 
interleukins (IL), colony-stimulating factors and erythropoietins have been used after that; since the end of 1990s - monoclonal antibodies and their varieties [3]. It must be noted that now it is one of the most rapidly developing segments of the pharmaceutical market. There are more than 150 BP now; ca. 370 BP more are on different stages of clinical studies [3]. It is also known that in 2003-2006 medicinal proteins accounted for more than 20\% of all innovative drugs approved in Europe and the USA by such agencies as the European Medicines Agency (EMEA) and Food and Drug Administration (FDA) [4]. We must also mention biological analogs, the role of which is becoming more prominent, especially in the developing countries, given the expiration of patents on many original medicinal proteins. Interpreting it money terms, given the current volume of the world pharmaceutical market, the BP share is $30 \mathrm{bn}$ dollars, while the share of biological analogs yet is ca. 10bn dollars [5].

There we must briefly enlarge upon definitions. According to one of the, a BP is a medicinal protein obtained using biotechnologies: recombinant DNA technology; controllable expression of genes encoding the synthesis of biologically active proteins; method of monoclonal antibodies etc. [3].

It is indisputable that such an interest to medicinal proteins is caused by their high clinical efficacy and broad range of indications to use. Areas of use of them are extremely versatile: endocrinology, oncology, rheumatology, oncohematology and hematology. The modern leaders in the group of BP are monoclonal antibodies to various receptors, enzymes and macroorganism's cells [6-11]:

- tumor necrosis factor (anti-TNF) - treatment of psoriasis, Crohn's disease and rheumatoid arthritis [infliximab (Remicade), adalimumab (Humira)];

- pre-B lymphocytes and mature B-lymphocytes - lymphomas, rheumatoid arthritis, chronic lymphatic leukemia [rituximab (Mabthera), ofatumumab (Arzerra)];

- vascular endothelial growth factor receptors - metastatic colorectal cancer, metastatic non-small-cell lung cancer, metastatic breast carcinoma and renal cell carcinoma [bevacizumab (Avastin)];

- human epidermal growth factor - disseminating breast cancer [trastuzumab (Herceptin)];

- epidermal growth factor receptor (EGFR) - colorectal cancer and brain tumor [cetuximab (Erbitux), panitumumab (Vectibix)];

- interleukin 12 and 23 - psoriasis [ustekinumab (Stelara)];

- interleukin 6-rheumatoid arthritis [tocilizumab (Actemra)].

Moreover, a part of proteins aimed at treating oncological and rheumatic diseases has become an ideological platform for the so called target therapy [12]. 
At the same time, the issues of pharmacological safety of these drugs, namely the rate and structure of adverse phenomena or side reactions (AdR), are not always clear and causes suspicion in many experts. The preparations used as immunosuppressants and antineoplastic agents deserve great attention in the first place.

The aim of this literary review is to find information on the adverse phenomena observed at the use of biopharmaceuticals used as immunosuppressants and antineoplastic agents.

\section{METHODS}

We conducted a systematic analysis of publications from 1990 to 2013 in order to reveal the studies dedicated to the research of adverse reactions of medicinal proteins. We searched the systems "MEDLINE", "Cochrane Library" and "EMBASE". The keywords were "biologics", "pharmacovigilance", "biopharmaceutical", "safety profile of biologicals", "adverse drug reactions of biopharmaceuticals" etc.

Inclusion criteria. The analysis involved publications describing AdR of medicinal proteins from the group of immunosuppressants and antineoplastic agents. We used the anatomical therapeutic chemical classification (ATC), by which we distinguished "Antineoplastic and immunomodulating agents" (L), which is subdivided into the following subgroups: "Antineoplastic agents" (L01), "Endocrine therapy" (L02), "Immunostimulants" (L03) and "Immunosuppressants" (L04).

Exclusion criteria. The analysis did not involve publications aimed at analyzing AdR of small molecules (SM). We excluded data on insulin drugs, vaccines, serums, immunoglobulins and toxoids. We did not analyze AdR of biological analogs (biosimilars).

We defined AdR as negative reactions connected with the use of a medicinal product in regular doses, which is used to prevent, diagnose or treat diseases and also to alter physiological functions [4].

We used the classification of adverse phenomena, which distinguishes between 4 types: A, B, C and D [13].

- Type A is characterized by reactions caused by the drug's pharmacological properties. They are usually predictable, frequent and dose-dependent; they are characterized by low lethality.

- Type B is characterized by immunoallergic reactions; they are unpredictable, doseindependent and appear less often. These reactions are often severe and have an unfavorable outcome.

- Type $\mathrm{C}$ - reactions appearing after a prolonged therapy; as a result, a patient may develop new disease; there may be an increase in the rate of "spontaneous" diseases. 
- Type D - delayed reactions (carcinogenic, mutagenic, teratogenic effects, genital system's defects etc.). They may appear in months or years after treatment.

\section{RESULTS}

The primary analysis of a keyword "biopharmaceutical" revealed ca. 25,000 citations, using the exclusion criteria - 1,200 reports on AdR of medicinal proteins (from insulins to toxoids). Manual search considerably decreased number of reports - down to 60 publications.

Most BP, including the ones represented in the pharmaceutical market of the Russian Federation (RF), belong to the subgroups "Antineoplastic agents" (L01), "Immunostimulants" (L03) and "Immunosuppressants" (L04).

We applied the following criteria of significance of differences:

- odds ratio (OR) - OR of events in one group to the other;

- confidence interval (CI) - range of fluctuations of true values; the 95\% CI means that $95 \%$ of measures obtained in studies with the same sample size and structure are within the calculated interval;

- number needed to harm $(\mathrm{NNH})$ - the number of patients, who should receive experimental treatment to develop and adverse outcome in one more patient, in comparison with the control group patients; it is quoted together with the $95 \% \mathrm{CI}$;

- absolute risk (AbR) - absolute arithmetical difference in the rate of adverse outcomes in the treatment and control groups;

- $\mathrm{p}$ criterion - the chance that the observed reactions are accidental.

It was decided to call them true if this parameters was lower than 1:20 (0.05). We deemed study results statistically different at $\mathrm{p}<0.05$.

\section{Main differences between biopharmaceuticals and small molecules}

First of all, we must note that there a several factors distinguishing BP from SM (low-molecular drugs, chemical compounds and "typical drugs"). Medicinal proteins demonstrate high pharmaceutical variability mainly because they are synthesized by living systems (e.g., by cell cultures); as a result, all products are unique. These are undoubtedly more complex compounds, as BP proteins contain several chains of amino acids with three-dimensional structure. Molecular weight is also considerably bigger than of chemical compounds $[14,15]$.

\section{General adverse phenomena}

As for adverse phenomena, we should mention several basic ideas. AR are of course revealed in the preregistration stage of preclinical and clinical studies, which is why it may appear that there is enough time to observe the action of $\mathrm{BP}$, at least, not less, but sometimes even more than to observe SM effects. It is true that the overall average BP and SM observation time does not significantly differ in these stages: 7.4 years (2.5-11.4 years) and 5.0 years (2.5-10.0 years), 
respectively [16]. Type A adverse reactions, characterized by the $1-10 \%$ rate of manifestations, are revealed in this stage [13]. However, there are several factors that do not allow doing this to the full extent on the preregistration stage exactly in respect of biopharmaceuticals.

Firstly, medicinal proteins are more often indicated for managing severer diseases (oncological and oncohematological immunodeficiencies), which in their turn may significantly influence the drug's safety profile and the patient's condition, than SM. That is why it is more difficult to reveal the cause-effect relation $[6-8,17]$. It is also important that it is not always possible to track these phenomena through time, namely, efficacy [effect obtained in "ideal conditions" of randomized placebo-controlled trials (RCT)]. In the RCT stage in this category of patients, researchers rarely wait until there are all disease outcomes, both positive and negative [18]. The way the product will act in the real clinical practice conditions, in a potentially more versatile population of patients, with other drugs, may only be modeled [19].

Secondly, BP is a foreign protein, which is why there is a risk of an immunological response developing with the antibody formation (type B AR). It is well known that the risk of development of type $\mathrm{B}$ reactions is $0.1-1 \%$. Thus, they may be diagnosed only with spontaneous reports, i.e. in the postregistration stage.

Thirdly, AR may result from inner properties of molecules and be built directly into their action mechanism. Many BP are immunosuppressants and their efficacy directly correlates with the immunosuppression level, i.e. with the risk of development of opportunistic infections (caused by opportunistic flora [20]. Thus, the risk of development of type C AR, which are also characterized by low rate of manifestations, is revealed only with the "case-control" trials in the postregistration stage.

As medicinal proteins interfere with complex physiological processes on the level of organellae and the human cell biology is not always clear, there is a theoretical risk of development of the delayed type D adverse phenomena with low detection rate (less than $0.1 \%$ ). Diagnostics also requires "case-control" trials on the postregistration stage.

Thus, the postregistration observation stage - pharmacovigilance - plays a special role in respect of medicinal proteins [16]. We restate that pharmacovigilance is a science and branch of practical activity connected with detection, evaluation, interpretation and prevention of adverse consequences of pharmacotherapy or any other issue related to medical intervention. The main application of pharmacovigilance is the postregistration level of drug application [21].

It is in this stage that the significant difference of AR of medicinal proteins and SM was demonstrated (earlier it had only been theoretically assumed) [22, 23]. It was definitely revealed that the main adverse phenomena are immunological reactions (type B), infections (type C) and neoplasms (type D) [23]. 


\section{Tumors (type D adverse reactions)}

A meta-analysis of RCT regarding this issue was conducted in 2006. The authors used databases "EMBASE", "MEDLINE", "Cochrane Library", electronic base of abstracts of annual scientific conventions of the European League Against Rheumatism and the American College of Rheumatology [24]. The most complete information in this stage was about 2 antiTNF [infliximab (Remicade), adalimumab (Humira)], which were prescribed for 12 and more weeks to patients with rheumatoid arthritis. After all trials were processed using inclusion/exclusion criteria, the analysis included 9 trials. As a result, 3,493 patients received anti-TNF therapy, 1,512 patients - placebo. The authors calculated OR and the 95\% CI as statistical tools. As a result, total OR for the development of malignant tumors was 3.3 (95\% CI - 1.2-9.1). Malignant neoplasms were considerably more often revealed in patients receiving high doses than in patients receiving low doses of anti-TNF. In the treatment period of 6-12 months, the NNH was 154 (95\% CI - 91-500). The data of this and a range of other metaanalyses made the FDA to complex manufacturers of anti-TNF (such drugs as infliximab, etanercept, adalimumab, certolizumab pegol, golimumab) to include additional information into drug package leaflets. The changes concerned the warning of the risk of development of cancer diseases in children and adolescents taking these drugs to treat juvenile rheumatoid arthritis, inflammatory intestinal diseases, Crohn's disease and other inflammatory diseases. Analysis of oncopathology in children and adolescents, who have been taking anti-TNF, demonstrated the risk of development of cancer diseases after 30 treatment months (on the average). Ca. a half of the revealed diseases is lymphomas [25].

According to the data of Canadian researchers, all medicinal proteins for treating rheumatoid arthritis (adalimumab, anakinra, etanercept, infliximab and rituximab) registered in Canada had an increased risk of malignant neoplasms, including lymphomas and skin cancer [26]. However, it is still unclear to what degree does each of the BP increases the risk of malignant neoplasms. It is also unknown which of the drugs is the "leader". This requires further large-scale transnational trials ("case-control" trials or analyses of patients' records).

\section{Immunological reactions (type $B$ adverse reactions)}

It is true that the experts assumed from the very appearance of medicinal proteins that they will be characterized by unique AR. They assumed, in particular, that composition and molecular weight of proteins will provoke immunological reactions, i.e. synthesis of antibodies against the introduced proteins that the macroorganism recognizes as foreign [16]. One of the first large literary reviews on immunogenicity was published in 2002 [27]. The authors analyzed data concerning this issue of 12 years (1990-2002). The review demonstrated that all exogenous proteins, including medicinal proteins, are capable of inducing synthesis of antibodies in a 
human body. The rate of antibody formation varied depending on proteins and studies (depending on methods that the authors used for analysis and the laboratory facilities in whole). BP immunogenicity depended on many factors, including the patient's genetic background, type of the primary disease (managed by the drug), type of protein (human or animal), medicinal protein's introduction route and treatment duration. According to these authors' data, immunogenicity rate for insulins was ca. $44 \%$, for growth hormones $-16 \%$, for erythropoietins - 1 per 10,000 patients, for factor VIII $-35 \%$, for recombinant interferons $-2 \%$ and for interleukins $-20 \%$ [27].

The authors note that the technology of BP production, processing and storage (potential risk of contamination, which may alter the three-dimensional protein's structure by oxidizing or by forming aggregates) also significantly affected immunogenicity.

Later, these authors were studying clinical manifestations of immunogenicity of medicinal proteins in more detail [28]. They demonstrated that formation of antibodies to BP led to classic immune reactions - from loss of efficacy to systemic immune effects, such as allergy, anaphylaxis or serum sickness with/without adverse outcome. In this aspect, the "breakout" of pure red cell aplasia (Diamond-Blackfan anemia) - autoimmune hemolytic anemia with antibodies to bone marrow erythrokaryocytes (antibody-mediated pure red cell aplasia - PRCA) - in 2002 (AR population peak) among the patients who were taking one particular drug formula of recombinant human erythropoietin - epoetin alfa (Eprex, Johnson \& Johnson) attracts attention [29]. Rise in PRCA morbidity concurred with the replacement of human serum albumin, which the drug had included, to glycine and polysorbate 80 . The investigation showed that molecular structure of epoetin alfa and clinical characteristics of patients were of no significant role. Introduction route did not matter as well, as most PRCA-patients received the BP subcutaneously. It was assumed (most probably, correctly) that replacement of albumin to other substances may have forwarded protein denaturation or aggregate formation. Moreover, the cork vial lids were replaced by resin lids; this may also have affected PRCA.

The possibility of "reverse" response to target impact (e.g., at IL blockade) by the functional system of immune homeostasis and macrophage activation syndrome were only slightly taken into consideration.

\section{Infections (type $C$ adverse reactions)}

Infections are another adverse phenomenon; it is the most often diagnosed phenomenon in the setting of BP intake (may be classified as type C). Researchers used 2 directions to determine clear interconnection: postregistration meta-analysis of RCT and analysis of the real clinical practice observation trials' data, mainly based on the registers of patients. 


\section{Meta-analysis and systemic literary review}

Systematic search of literature was conducted in 2005 [24] concerning RCT of 2 anti-TNF (infliximab and adalimumab), which patients with rheumatoid arthritis had been taking for 12 weeks and more. As a result, total OR of development of opportunistic infections was 2.0 (95\% $\mathrm{CI}-1.3-3.1)$. NNH was $59(95 \% \mathrm{CI}-39-125)$ during the BP treatment period. All adverse phenomena required anti-infectious therapy.

Another systematic literary review was conducted later [30]. It used databases "PUBMED", "EMBASE", "Cochrane Library" and a database of theses (the American College of Rheumatology and the European League Against Rheumatism). The analysis included 20 RCT with 6,879 patients; 745, 1,960, 2,062 and 2,112 patients were receiving rituximab (antibodies to B lymphocytes), abatacept (blocker of costimulation of $\mathrm{T}$ lymphocytes), anakinra (recombinant antagonist of receptor IL 1) and placebo, respectively. In whole, no statistically significant increase in the risk of development of a serious infection was revealed in the group of antibodies to B lymphocytes and in the blocker of costimulation of $\mathrm{T}$ lymphocytes in comparison with placebo. At the same time, high doses of recombinant antagonist of receptor IL 1 were leading to the increase in the risk of infections.

\section{Prospective and retrospective observation trials of real practice}

70 confirmed cases of tuberculosis after infliximab treatment, 12 weeks after its beginning on the average, had been registered by 2001 [31]. More than a half of these patients had extrapulmonary tuberculosis forms, 17 - generalized forms. Out of the 70 episodes, almost all patients came from countries low rate of tuberculosis morbidity.

Listeriosis is another complication of anti-TNF treatment [32]. At any rate, according to the FDA data, 15 infection cases had been registered in the USA by 2001 in the setting of infliximab and etanercept intake. The average age of the patients was 69.5 years (ranging from 17 to 80 years); $53 \%$ of the infected were women. Adverse outcome (death) was registered in 6 patients.

\section{Use of registers of patients}

A prospective observation trial was conducted in order to compare the rate of infections in patients with rheumatic diseases receiving anti-TNF with patients receiving traditional therapy [33]. According to the national registers of patients with rheumatic diseases in Great Britain, 7,664 patients received anti-TNF, 1,354 - traditional SM therapy. The analysis included all infection cases, including serious cases. It showed that 525 opportunistic infections were registered in the group of patients receiving anti-TNF and 56 - in the control group (in observation man-years $-9,868$ and 1,352, respectively) - in 2001-2005. The rate of serious 
infections of skin and soft tissues was considerably higher in the anti-TNF group -4.28 (95\% CI - 1.06-17.17). As a result, the authors concluded that anti-TNF intake does not lead to considerable increase in the total rate of opportunistic infections. However, the rate of serious infections of skin and soft tissues increased considerably.

The rate of infections in the setting of intake of medicinal proteins in patients $\geq 65$ years of age (average age - 76.5 years) was analyzed in the USA in 2007 on the basis of the "Medicare" database [34]. The study altogether included 16,000 patients with rheumatic arthritis who underwent BP therapy in 1995-2003. It has been one of the largest studies, which would use such a methodological approach. Such parameter as AbR was used for statistical processing. The average rate of serious bacterial infections was 2.2 per 100 patient-years. The corrected model, which took into account glucocorticoid therapy, did not show an increase in the rate of serious bacterial infections among the patients, who received anti-TNF [AbR - $1.0(95 \% \mathrm{CI}-$ 0.6-1.7)], not SM (methotrexate).

At approximately the same time a retrospective cohort study of patients with rheumatoid arthritis, who had been receiving either anti-TNF or methotrexate, was conducted in the USA on the basis of insurance companies [35]. As a result, bacterial infections were registered in 2,393 patients (observation period - 3,894 human-years), who had been receiving anti-TNF, and in 2,933 (4,846 human-years), who had been receiving methotrexate. The rate of hospitalizations with the confirmed bacterial infection within the observation period (17 months) was $2.7 \%$ in patients, who had been receiving anti-TNF, in comparison with $2.0 \%$ in patients, who had been receiving only methotrexate. The infectious morbidity was the highest within the first 6 months after anti-TNF therapy beginning (2.9 and 1.4. cases per 100 humanyears). Thus, the authors concluded that the rate of bacterial infections is ca. 2-4 times higher among patients receiving anti-TNF than in patients receiving only methotrexate.

Another retrospective study analyzed 100 cases of infectious complications of etanercept and infliximab treatment of rheumatic diseases [36]. 2 patients were diagnosed with pulmonary tuberculosis and hepatitis B, 9\% - with herpetic infection (zoster). In the end, total infectious morbidity after anti-TNF treatment was 0.122 or 0.201 per 1 human-year. Herpetic infection is indeed one of the most frequent infections appearing in the setting of BP intake. Thus, 86 zoster cases were registered among 5,040 patients in the setting of infliximab, etanercept and adalimumab treatment in 2001-2006 [37]. Total morbidity rate per 1,000 human-years was 11.1 (95\% CI - 7.9-15.1) for monoclonal antibodies and 5.6 (95\% CI - 3.6-8.3) for SM.

\section{Large-scale studies}


Perhaps the first large-scale study of AR of medicinal proteins was conducted in 2010. The data for 1995-2008 were taken from the international database of adverse phenomena (VigiBase) supported by the World Health Organization [22]. The analysis did not include information on vaccines and toxoids. Medicinal proteins were divided into several classes: monoclonal antibodies, cytokines, enzymes, growth factors and interferons. As a result, the analysis included 191,004 AR reports. It revealed that 2/3 of all averse phenomena were registered for 5 drugs: etanercept (receptor blocker) - 20.3\%, interferon $\beta-1 \mathrm{a}-15.6 \%$, infliximab (antibodies) $11.6 \%$, teriparatide (receptor blocker) - 10.7\% and adalimumab (antibodies) - 9.0\%. Comparison of the safety profile of biopharmaceuticals with the SM (hormones) control group showed that AR of medicinal proteins were most often interpreted as "infections" $(8.7 \%)$ and "benign, malignant or unspecified neoplasms" (2.3\%), rarely - as "mental disorders" and "vascular disorders" (pic. 1). Thus, type C and type D AR were the most frequent.

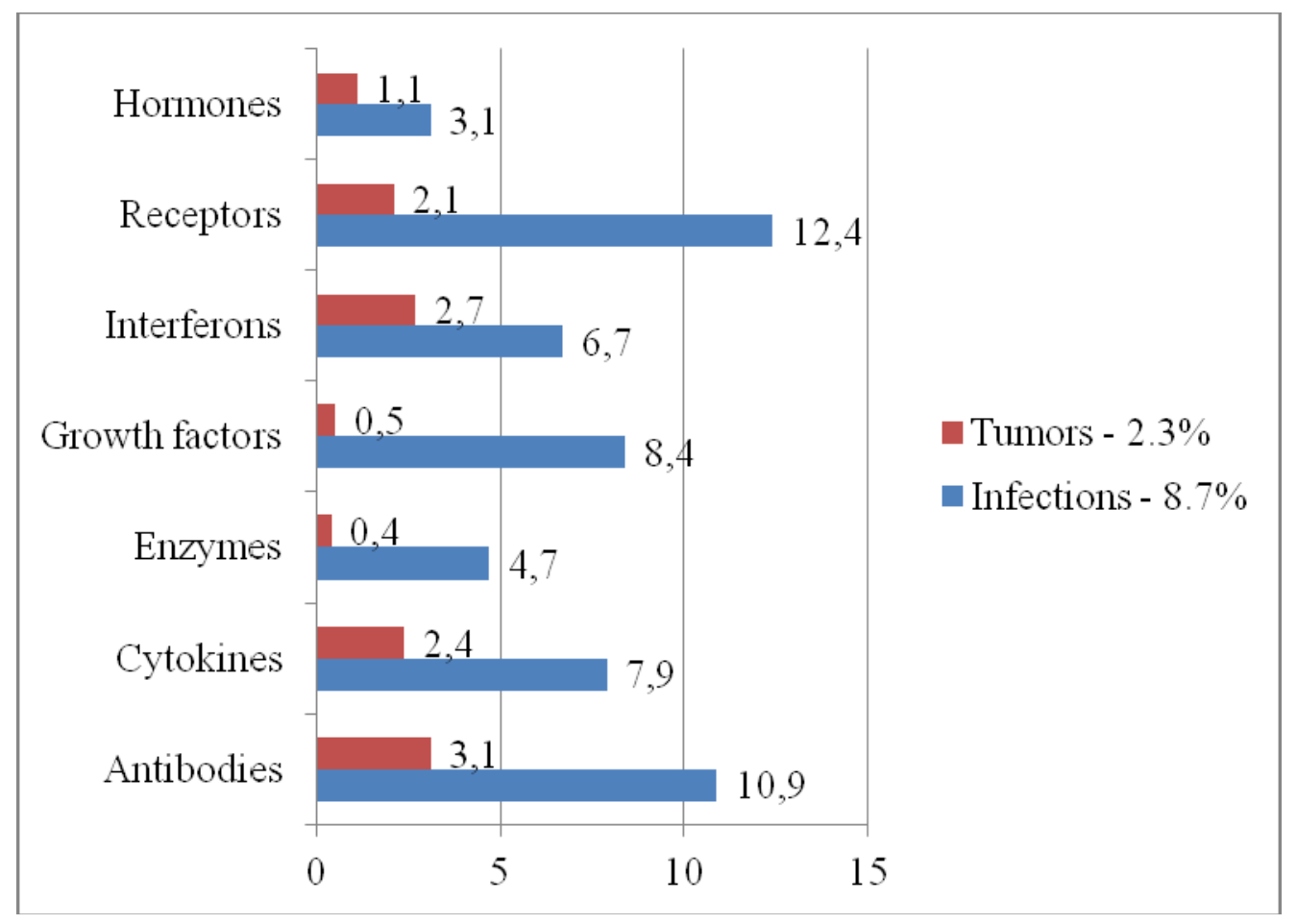

Pic. 1. Rate of adverse reactions within the group of biopharmaceuticals (\%).

One of the latest studies dedicated to the issue of safety of medicinal proteins in comparison with SM was conducted by H. Ebbers et al. in 2013 [38]. The authors analyzed the AR revealed in the postregistration life cycle stage of the drugs of the same ATC classification group "Antineoplastic and immunomodulating agents" ('L'), which were approved in the European Union in 1995-2011. Total rate of adverse reactions in medicinal proteins and chemical substances was not significantly different - 361 and 386 episodes, respectively. The structure 
was different; it was best manifested in the subgroup of immunosuppressants (pic. 2). Out of all AR (747 cases), BP were significantly more often characterized by neoplasms (20 and 2\%, $\mathrm{p}<0.01$ ) and severe infections (22 to $9 \%, \mathrm{p}<0.01) .58 \%$ out of 38 infectious episodes were registered in the setting of anti-TNF intake. The immune system disorders in the subgroup of antineoplastic agents were more often associated with BP than with SM as well -6 to $1 \%$, respectively $(\mathrm{p}=0.04) .4$ infections out of 7 were connected with rituximab. Moreover, $85 \%$ out of $35 \mathrm{AR}$, classified as neoplasms, were associated with anti-TNF.

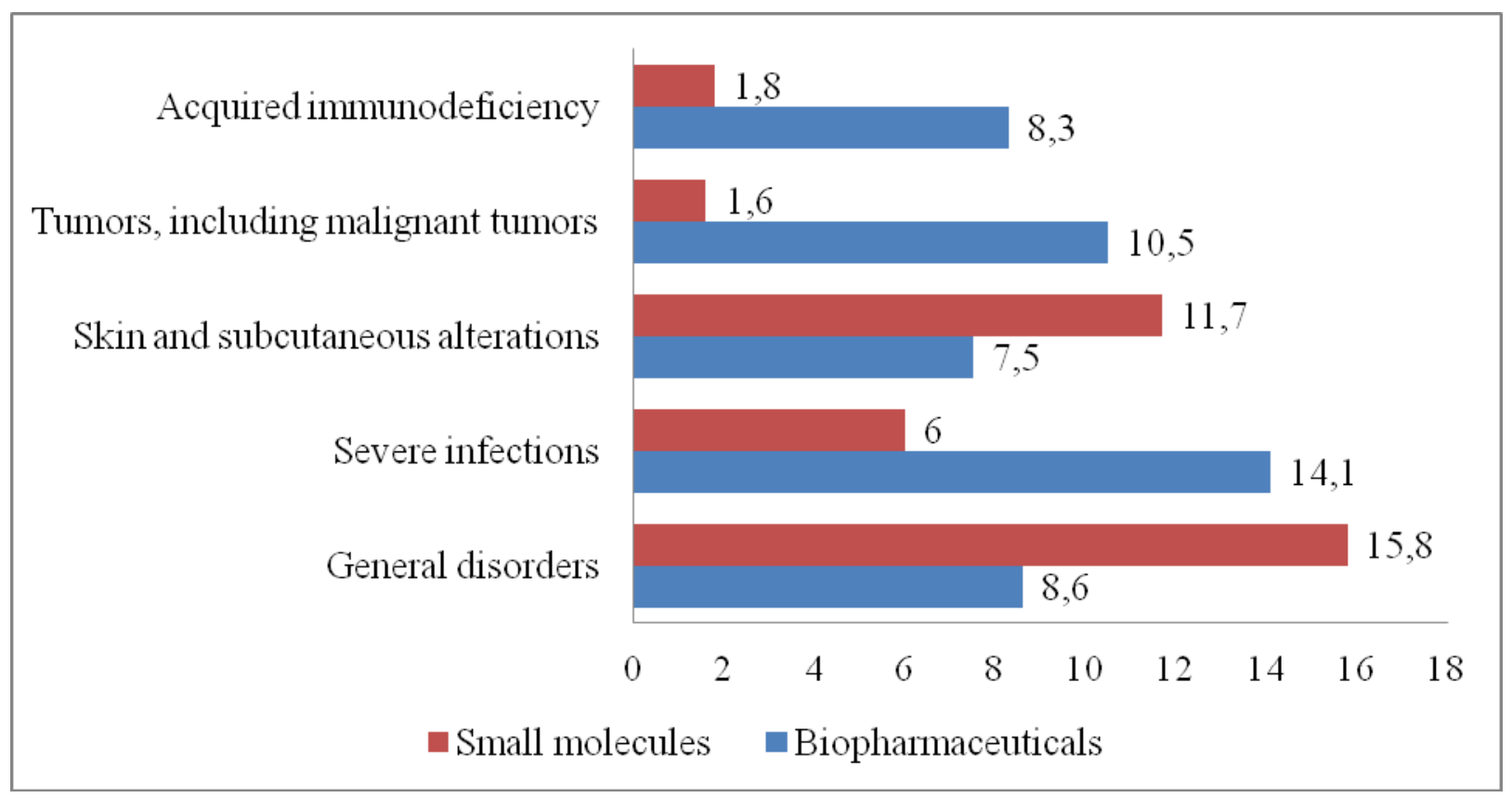

Pic. 2. Rate and structure of the most frequent adverse reactions ( $n=747)(\%)$ [38].

The spread according to the AR localization was as follows: adverse reactions in kidneys and urinary tracts ( 7 to $0 \%, \mathrm{p}<0.01$ ), blood and lymphatic system $(10$ to $3 \%, \mathrm{p}=0.04)$ and vascular disorders ( 7 to $1 \%, \mathrm{p}=0.02$ ) were revealed more often with chemical substances than with medicinal proteins [38].

In conclusion it should be noted that in the beginning of 2000 s it was assumed that the AR detection time for proteins may differ from the detection time for SM [23, 39]. It was not confirmed in later years. The conducted analysis showed that there is no statistically significant difference in the realization time of an adverse phenomenon (the first episode): for BP -18 months, for SM - 17 months [38].

\section{DISCUSSION}

Medicinal proteins are a crucial element of treating various severe and even life-threatening diseases [40]. The modern leaders are monoclonal antibodies. At the same time, a wide range of 
indications to their use is suspicious. They may take the same historical route as interferons (alfa, beta and gamma). We remember that scientists were setting great expectations on interferons from the moment they had been introduced in clinical practice - from managing (preventing and treating) infections to treating oncological diseases. As is well known, it has never come true to the expected extent, and now the international acknowledged indications to their use are extremely narrow: for interferons alfa - a range of oncological and oncohematological diseases, out of viral infections - only viral hepatites; for interferons beta disseminated sclerosis; interferon gamma is not used in clinical practice. However, Russian scientific thought "got stuck in the 70s" in terms of this aspect and still features multiple indications.

In comparison with the traditional chemically synthesized SM, biological pharmaceuticals have special characteristics affecting their safety profile. E.g. BP are more complex molecules with special production and limited predictability of clinical outcomes [16, 41, 42]. These and other peculiarities may lead to the increase in uncertainty in terms of safety profile of biological pharmaceuticals at the moment of registrations; this has been confirmed by a range of studies.

We restricted our study to the most interesting BP group - monoclonal antibodies and their variations. The best studied AR associated with these proteins are their immunological reactions and infections. This mainly concerns the use of anti-TNF in rheumatologic patients. Infections in the group of patients with oncohematological disease have been poorly studied. Such AR as potential carcinogenicity have been studied insufficiently, just as the group of patients receiving BP to treat oncological diseases. This is most probably caused by the fact that it is extremely difficult to track and diagnose carcinogenicity from the causal-effect point of view.

A clear tendency is observed: the AR rate is significantly lower in the meta-analysis of RCT than in the real clinical practice observation trials. At any rate, is very vivid in the analysis of such phenomenon as infection.

Given the specific AR profile of medicinal proteins, several experts suggest rather radical measures - to change the classic classification of adverse phenomena. It has historically been established that AR are classified into 4 types $-\mathrm{A}, \mathrm{B}, \mathrm{C}$ and $\mathrm{D}$. This classification has a range of restrictions and is criticized more and more [13]. The conducted studies showed that the most frequent adverse phenomena were of type B (immunoallergic reactions) and type C (infections). Type D (carcinogenic effects) takes the $2^{\text {nd }}$ place. Types $C$ and D may probably remain the most frequent for medicinal proteins in the future. Many authors suggest new BP classifications based on immunological reactions [43-45]. Thus, they suggest differentiating between 5 different types [46, 47]: 
- clinical reactions caused by the high level of cytokines (type alfa);

- hypersensitivity due to immune reaction to biological agents (type beta);

- immune and cytokine imbalance syndrome (type gamma);

- cross-reactivity syndrome (type delta);

- symptoms affecting immune system indirectly (type epsilon).

The second strategic approach is the change of traditional registration and safety monitoring measures for medicinal proteins. It is especially vivid in new directives of the European Union, which significantly extend the pharmacovigilance responsibility area [48].

Foundation of a new scientific committee within the EMEA - pharmacovigilance risk assessment committee - is a fundamental change. It is responsible for a big number of functions, but the ability to approve or reject protocols of postregistration safety studies, determination of periodical safety reporting frequency for product marketing authorization holders, development and publication of a list of medical products requiring additional monitoring attract special attention [49, 50]. The directive introduces a fundamentally new notion - pharmacovigilance system's base file, i.e. detailed description of the pharmacovigilance system in respect of the product. The file may be available upon request at any time. Gathering of spontaneous reports is facilitated by the registration of all reports in the common database of the European Union - "Eudravigilance". It is also necessary to make a list of drugs subject to the additional postregistration monitoring. All new substances and biological products, including biological analogs, will belong to such products. Another novelty is the fact that the information list of such products will contain a black square, their list will be constantly updated and available on the Internet.

Most experts assign a special role to the so called risk management [4, 45]. Risk management is defined as the combination of activity and measures in the area of pharmacovigilance aimed at detection, prevention and reduction of risks connected with drugs. It is based on the risk management plan, which includes the description of potential risks, pharmacovigilance stages and evaluation of the need in additional measures to reduce risks. E.g. ca. $1 / 4$ of BP package leaflets (41 out of 174) registered in the countries of the European Union and the USA were altered in the middle of 2000s in the post-approval period. Risk reduction measures included 46 warning letters, 10 warnings highlighted by black frame and 17 direct meetings with professionals [4].

This work did not aim at analyzing situation with biological analogues (biosimilars). However, we must mention that the system of monitoring AR of biological analogues cannot be applied 
on the basis of the requirements imposed on the patented drugs. Although a biological analog and a comparator may have similar efficacy, analogs may have various adverse reactions in terms of their nature, seriousness and frequency [51, 52]. Biological analog's pharmacosafety must be thoroughly controlled on the regular basis in the postregistration period, using the risk management techniques as well. Risk management plan for bioanalogs should focus on the reinforcement of pharmacovigilance measures. According to many experts, all medicinal proteins should only have a trade name, a brand name and an indication of manufacturer [51].

\section{CONCLUSIONS AND RECOMMENDATIONS}

Medicinal proteins indisputably require an optimized pharmacovigilance system with AR planning or management (risk management). The new directive of the European Union introduced in July 2012 inspires a particular hope. If it is actually introduced and starts working, this will signify a considerable progress in the BP safety. Unfortunately, the drug safety monitoring system in the RF remains an outsider of international processes.

Perhaps, a new classification of adverse phenomena must be developed to interpret AR of biological pharmaceuticals, which will be based on the macroorganism's immunological response mechanisms. It is extremely important to improve prognostication of delayed reactions, especially of carcinogenicity. Such areas of pharmacology as pharmacometrics may help to do this.

An increase in the number of Russian biological analogs in the RF practical health care causes particular suspicion. In the setting of clear doctoral understanding that bioanalog is not a generic of a chemical substance, but often an absolutely new biological pharmaceutical, the RF encounters with a unique problem. Given an extremely weak RF pharmacovigilance system, we obtain information on the adverse reactions of drugs from the data of our foreign colleagues, as the original drugs are used in other countries as well. We must admit that we know almost nothing about the situation in the RF. Introducing Russian bioanalogs, we encounter with "Pandora's box" given that they are not used anywhere else in the world. It is impossible to predict what will happen to patients, what AR will develop; it is also impossible yet to monitor them in the RF. The situation will probably improve and people responsible for the health care system will finally draw their attention to the pharmacosafety system. We would like that to be a relevant ministry; not departments responsible for the construction of factories, support of pharmaceutical clusters or departments influencing public purchases. It appears that their functional responsibilities do not involve provision of the RF citizens with efficient and safe drugs in the belief that this will increase life expectancy (and improve life quality) of the citizens. 


\section{Study restriction}

We initially excluded data on vaccines, serums, immunoglobulins and toxoids from this review.

We deem extremely interesting an analysis of AR of insulins, especially in the setting of the modern Russian tendency of replacing original drugs with biological analogs. The analysis involved only few data on interferons and interleukins; this seems to be the weakest part of the work. The main reason for this is that we used international databases, starting usually with the 1990s, whereas data on AR of interferons had already been published by that time. It is likely to be our next work.

\section{REFERENCES}

1. Motola D., De Ponti F., Poluzzi E., Martini N., Rossi P., Silvani M.C. et al. An update on the first decade of the European centralized procedure: how many innovative drugs? Br. J. Clin. Pharmacol. 2006; 62 (5): 610-6.

2. Trusheim M.R., Aitken M.L., Berndt A.R. Characterizing markets for biopharmaceutical innovations: do biologics differ from small molecules? Forum Health Econ. Pol. 2010; 13 (1): $1-45$.

3. Available at: www.bio.org.

4. Astakhova A.V., Lepakhin V.K. Federal Center of Drug Safety Monitoring. The role of the risk management system in the prevention of pharmacotherapy complications. Available at: http://www.rspor.ru

5. Available at: http://www.kaloramainformation.com

6. Naldi L. Malignancy concerns with psoriasis treatments using phototherapy, methotrexate, cyclosporin, and biologics: facts and controversies. Clin. Dermatol. 2010; 28 (1): 88-92.

7. Smolen J.S., Landewe R., Breedveld F.C., Dougados M., Emery P., Gaujoux-Viala C. et al. EULAR recommendations for the management of rheumatoid arthritis with synthetic and biological disease-modifying antirheumatic drugs. Ann. Rheum. Dis. 2010; 69 (6): 964-975.

8. Pathirana D., Ormerod A.D., Saiag P., Smith C., Spuls P.I., Nast A., Barker J., Bos J.D. et al. European S3-guidelines on the systemic treatment of psoriasis vulgaris. J. Eur. Acad. Dermatol. Venereol. 2009; 23 (2): 1-70.

9. Singh J., Christensen R., Wells G.A., Suarez-Almazor Maria E., Buchbinder R., Lopez-Olivo Maria A. et al. Biologics for rheumatoid arthritis: an overview of Cochrane reviews. Cochrane Database Syst. Rev. 2009; 4: CD007848.

10. Alonso-Ruiz A., Pijoan J.I., Ansuategui E., Urkaregi A., Calabozo M., Quintana A. Tumor necrosis factor alpha drugs in rheumatoid arthritis: systematic review and metaanalysis of efficacy and safety. BMC Musculoskelet Disord. 2008; 9: 52.

11. Mazurov V.I. Klinicheskaya revmatologiya. Rukovodstvo dlya prakticheskikh vrachei. 2-e izd. [Manual for Practicing Physicians. $2^{\text {nd }}$ edition] St. Petersburg, Foliant, 2005. 520 p.

12. Available at: http://www.rosoncoweb.ru

13. Aronson J.K. Adverse drug reactions: history, terminology, classification, causality, frequency, preventability. Stephens' Detection and evaluation of adverse drug reactions. New York, Wiley Ltd, 2011. pp. 1-119.

14. Clark J.B. Mechanisms of adverse drug reactions to biologics. In: Uetrecht J., editor. Adverse drug reactions. Berlin, Springer, 2010. pp. 453-474.

15. Baumann A. Early development of therapeutic biologics: pharmacokinetics. Curr. Drug

Metab. 2006; 7 (7): 15-21.

16. Giezen T.J., Mantel-Teeuwisse A.K., Leufkens H.G. Pharmacovigilance of

biopharmaceuticals: challenges remain. Drug Saf. 2009; 32 (10): 811-817. 
17. Doran M.F., Crowson C.S., Pond G.R., O'Fallon W.M., Gabriel S.E. Predictors of infection in rheumatoid arthritis. Arthritis Rheum. 2002; 46 (9): 2294-2300.

18. Kolbin A.S., Kurylev A.A., Pavlysh A.V., Proskurin M.A., Balykina Yu.E. Scientific analysis of outcomes in oncology. Peculiarities of pharmacoeconomic examination. Med. tekhnol. Otsenka i vybor - Medical technologies. Assessment and selection. 2012; 2 (8): 87-93. 19. Kleijnen S., George E., Goulden S., d'Andon A., Vitre P., Osinska B., Rdzany R., Thirstrup S., Corbacho B. et al. Relative effectiveness assessment of pharmaceuticals: similarities and differences in 29 jurisdictions. Value In Health. 2012; 15: 954-960.

20. Vial T., Descotes J. Immunosuppressive drugs and cancer. Toxicology. 2003; 185 (3): 22940.

21. Lepakhin V.K., Ushakova E.A., Astakhova A.V. The role of a clinical pharmacologist in the drug therapy safety improvement. Bezopasnost' lekarstv i farmakonadzor - Drug safety and pharmacovigilance. 2008; 1: 5-11.

22. Giezen T.J., Mantel-Teeuwisse A.K., Meyboom R.H., Sabine M.J.M. Straus, Hubert G.M. Leufkens, Toine C.G. Egberts. Mapping the safety profile of biologicals: a disproportionality analysis using the WHO adverse drug reaction database, VigiBase. Drug Saf. 2010; 33 (10): 865-878.

23. Giezen T.J., Mantel-Teeuwisse A.K., Straus S.M., Huub Schellekens, Hubert G. M. Leufkens, Antoine C. G. Egberts. Safety-related regulatory actions for biologicals approved in the United States and the European Union. JAMA. 2008; 300 (16): 1887-1896.

24. Bongartz T., Sutton A.J., Sweeting M.J., Buchan I., Matteson E.L., Montori V. Anti-TNF antibody therapy in rheumatoid arthritis and the risk of serious infections and malignancies: systematic review and meta-analysis of rare harmful effects in randomized controlled trials. JAMA. 2006; 295 (19): 2275-2285.

25. Available at: http://www.fda.gov

26. Khraishi M. Comparative overview of safety of the biologics in rheumatoid arthritis. $J$. Rheumatol. Suppl. 2009; 82: 25-32.

27. Schellekens H. Immunogenicity of therapeutic proteins: clinical implications and future prospects. Clin. Ther. 2002; 24 (11): 1720.

28. Schellekens H. Factors influencing the immunogenicity of therapeutic proteins. Nephrol. Dial. Transplant. 2005; 20 (6): 3-9.

29. Locatelli F., Del Vecchio L., Pozzoni P. Pure red-cell aplasia «epidemic» - mystery completely revealed? Perit. Dial. Int. 2007; 27 (2): 303-307.

30. Salliot C., Dougados M., Gossec L. Risk of serious infections during rituximab, abatacept and anakinra treatments for rheumatoid arthritis: meta-analyses of randomised placebocontrolled trials. Ann. Rheum. Dis. 2009; 68 (1): 25-32.

31. Keane J., Gershon S., Wise R.P. Tuberculosis associated with infliximab, a tumor necrosis factor alpha-neutralizing agent. N. Engl. J. Med. 2001; 345 (15): 1098-1104.

32. Slifman N.R., Gershon S.K., Lee J.H., Edwards E.T, Braun M.M. Listeria monocytogenes infection as a complication of treatment with tumor necrosis factor alpha-neutralizing agents. Arthritis Rheum. 2003; 48 (2): 319-324.

33. Dixon W.G., Watson K., Lunt M., Hyrich K.L., Silman A.J. Rates of serious infection, including site-specific and bacterial intracellular infection, in rheumatoid arthritis patients receiving anti-tumor necrosis factor therapy: results from the British Society for Rheumatology Biologics Register. Arthritis Rheum. 2006; 54 (8): 2368-2376.

34. Schneeweiss S., Setoguchi S., Weinblatt M.E., Katz J.N., Avorn J., Sax P.E., Levin R., Solomon D.H. Anti-tumor necrosis factor alpha therapy and the risk of serious bacterial infections in elderly patients with rheumatoid arthritis. Arthritis Rheum. 2007; 56 (6): 17541764.

35. Curtis J.R., Patkar N., Xie A., Martin C., Allison J.J., Saag M., Shatin D., Saag K.G. Risk of serious bacterial infections among rheumatoid arthritis patients exposed to tumor necrosis factor alpha antagonists. Arthritis Rheum. 2007; 56 (4): 1125-1133. 
36. Suwannalai P., Auethavekiat P., Udomsubpayakul U. The infectious profiles of anti-tumor necrosis factor agents in a Thai population: a retrospective study a the university-based hospital. Int. J. Rheum. Dis. 2009; 12 (2): 118-124.

37. Strangfeld A., Listing J., Herzer P., Liebhaber A., Rockwitz K., Richter C. et al. Risk of herpes zoster in patients with rheumatoid arthritis treated with anti-TNF-alpha agents. JAMA. 2009; 301 (7): 737-744.

38. Ebbers H.C., Al-Temimi E., Moors E.H., Mantel-Teeuwisse A.K., Schellekens H., Leufkens H.G. Differences between postauthorization adverse drug reactions of biopharmaceuticals and small molecules. BioDrugs. 2013. DOI 10.1007/s40259-013-0012-y.

39. Lasser K.E., Allen P.D., Woolhandler S.J., Himmelstein D.U., Wolfe S.M., Bor D.H. Timing of new black box warnings and withdrawals for prescription medications. JAMA. 2002; 287 (17): 2215-2220.

40. Crommelin D.J., Storm G., Verrijk R., de Leede L., Jiskoot W., Hennink W.E. Shifting paradigms: biopharmaceuticals versus low molecular weight drugs. Int. J. Pharm. 2003; 266 (12): $3-16$.

41. Schellekens H. How similar do 'biosimilars' need to be? Nat. Biotechnol. 2004; 22 (11): 1357-1359.

42. Brennan F.R., Shaw L., Wing M.G., Robinson C. Preclinical safety testing of biotechnologyderived pharmaceuticals: understanding the issues and addressing the challenges. Mol.

Biotechnol. 2004; 27 (1): 59-74.

43. Ferner R.E., Aronson J.K. EIDOS: a mechanistic classification of adverse drug effects. Drug Saf. 2010; 33 (1): 15-23.

44. Pichler W.J. Adverse side-effects to biological agents. Allergy. 2006; 61 (8): 912-920.

45. Shankar G., Pendley C., Stein K.E. A risk-based bioanalytical strategy for the assessment of antibody immune responses against biological drugs. Nat. Biotechnol. 2007; 25 (5): 555-561.

46. Hausmann O.V., Seitz M., Villiger P.M. The complex clinical picture of side effects to biologicals. Med. Clin. North Am. 2010; 94 (4): 791-804.

47. Zemkova M., JebavH L., Kotlarova J., Jiri Vlcek, Ronald H.B. Meyboom. The spectrum and types of adverse side effects to biological immune modulators: a proposal for new classification Folia Biol. (Praha). 2007; 53 (4): 146-155.

48. Kolbin A.C., Burbello A.T., Zagorodnikova K.A. Pharmacovigilance in the Russian Federation and the united Europe in the setting of the new directive of the European Union. Will there be changes? Remedium - Remedium. 2012; 8 (186): 8-14.

49. Fitt $H$. The new pharmacovigilance legislation: an EMA perspective. - IPA Conference Reinforcing patient safety in Europe, 2011. Available at:

www.ema.europa.eu/docs/en_GB/document_library/Presentation/2011/06/WC500107888.pdf (accessed: 05.07.12).

50. The European Parliament and the Council of the European Union. Regulation (EU) No 1235/2010 of the European Parliament and of the Council of 15 December 2010 amending, as regards pharmacovigilance of medicinal products for human use, Regulation (EC) No 726/2004 laying down Community procedures for the authorization and supervision of medicinal products for human and veterinary use and establishing a European Medicines Agency, and Regulation (EC) No 1394/2007 on advanced therapy medicinal products [online]. Available at: http://eurlex.europa.eu/LexUriServ/LexUriServ.do?uri=OJ:L:2010:348:0001:0016:EN:PDF (accessed: 05.07.12).

51. Mellstedt H., Niederwieser D., Ludwig H. The challenge of biosimilars. Ann. Oncol. 2008; 19 (3): 411-419.

52. Zuciga L., Calvo B. Biosimilars: pharmacovigilance and risk management.

Pharmacoepidemiol. Drug Saf. 2010; 19 (7): 661-669. 